\title{
UTILIZATION OF TEXTILE FIBRES FROM WORN AUTOMOBILE TIRES IN CEMENT BASED MORTARS
}

\section{S. MAVRIDOU* \\ N. OIKONOMOU}

\author{
Laboratory of Building Materials \\ Department of Civil Engineering \\ Aristotle University of Thessaloniki \\ 54124, Thessaloniki, Greece
}

Received: 23/12/09

Accepted: 12/10/10 *to whom all correspondence should be addressed: e-mail: smavrido@civil.auth.gr

\begin{abstract}
This research paper focuses on the properties of laboratory made cement mortars modified with textile from worn automobile tires. Textile, in the form of fibres, has been added to cement mortars at various percentages of total cement mortar volume, which ranged from $0-2.0 \%$. Properties of mortartextile-aggregates mixtures such as consistency-workability-, bulk density as well as mechanical ones such as dynamic modulus of elasticity, compressive and flexural strengths have been studied. Moreover, water absorption under vacuum and capillarity by suction of such mixtures have been measured, as a preliminary examination of cement mortars' durability. The study of the mixtures has been completed by the observation of their microstructure. All properties have been tested according to European Specifications.

Laboratory results showed that properties of cement mortars, modified with textile from worn automobile tires, were found to be familiar to the ones of the control mixture (with no additive). Incidentally, a solid waste material such as textile fibers from worn automobile tires can be utilized properly in cement products providing an opportunity to recycle non-reusable end of life tires and as a result contributing to the protection of the environment.
\end{abstract}

KEYWORDS: environment, tires, composites, mechanical characteristics, durability, microstructure.

\section{INTRODUCTION}

The amount of rubber tires disposed in Greece is roughly 58500 tones ( 250000 pieces) per year (E.T.R.A, 2006). Landfill disposal of worn mobile tires is drastically reduced due to European Directives and Greek legislation (Presidential Decree No.109, 2004), which include restrictions on this practice in favor of alternatives oriented towards materials and energy recovery. Moreover, the disposal of worn mobile tires, often uncontrollable, increases the risk of fire hazards with toxic emissions to the atmosphere. In order to dispose properly these stockpiles of worn mobile tires, the use of innovative techniques to recycle them is important.

Many studies have been conducted on the possible use of rubber from worn mobile tires in a variety of civil and non civil engineering projects. In Greece, the most common uses of tire rubber are for the production of electricity, incineration in cement kiln as alternative fuel or for the production of secondary rubber composites. As far as Civil Engineering works are concerned, many efforts have been made towards production of cement based composites such as concrete, road barriers, kerb units and pedestrian blocks (Topçu, 1995; Nehdi and Khan 2001; Sukontasukkul and Chalermphol, 2006; Oikonomou and Mavridou, 2008), in road construction and other geotechnical works. In Greece, addition of rubber from worn mobile tires has been studied in cement mortars and concrete mixtures for kerb units and paving blocks with satisfactory results (Oikonomou et al., 2007).

However, another recyclable composite of mobile tires is textile, which is removed after the shredding of the end-of-life tires. Automobile tires contain textile at percentages up to $5 \%$. Although the percentage is not as high as the one of rubber $(\sim 50 \%)$, it is a waste which needs to be properly 
utilized (E.T.R.A, 2006). This paper aims at studying the behavior of mortars modified with this sort of waste material.

\section{EXPERIMENTAL PART}

\section{Materials used}

The materials used for this study were cement, river sand, water and textile fibres.

The hydraulic binder was ordinary Portland Cement CEM IV/B 32.5, with specific gravity $3.15 \mathrm{gr} \mathrm{cm}^{-3}$ and has been supplied by TITAN S.A.

The river sand $(0-4 \mathrm{~mm})$ was of limestone origin.

Textile fibres have been taken after they have been removed from the products of worn mobile tires' mechanical shredding and have been supplied by Karambas S.A. Their specific gravity is $0.9 \mathrm{gr} \mathrm{cm}^{-3}$, while their water absorption is negligible. They have been added to the mixtures at different volumetric proportions of the total mixture. A conventional one has been prepared, while the rest of the compositions contained fibres at $0.2,0.4,0.6,0.8,1.0,1.2,1.6,2.0 \%$ of total mixture volume. Fibres were used as obtained as well as after been washed with water, in order that impurities are removed.

\section{Making up of test specimens}

Cement mixtures were cast in prism-shaped moulds $(40 \times 40 \times 160 \mathrm{~mm})$ and compacted by vibration. After 24 hours, the specimens were removed from the moulds and cured in water for 28 days at a temperature of $20 \pm 2{ }^{\circ} \mathrm{C}$.

\section{Mixture proportions}

The mixture proportions of all the compositions are showed in Table 1.

Table 1. Mixtures' proportioning

\begin{tabular}{|c|c|c|c|c|c|c|c|c|c|}
\hline \multirow{2}{*}{ Materials } & \multirow{2}{*}{ Fo } & $F 1(w)$ & $F 2(w)$ & $F 3(w)$ & $F 4(w)$ & $F 5(w)$ & F6(w) & $F 7(w)$ & $F 8(w)$ \\
\hline & & $\mathrm{F} 1(\mathrm{nw})$ & $\mathrm{F} 2(\mathrm{nw})$ & $F 3(n w)$ & $F 4(n w)$ & F5(nw) & F6(nw) & $\mathrm{F} 7(\mathrm{nw})$ & F8(nw) \\
\hline $\begin{array}{l}\text { Cement, CEM } \\
\text { IV/B } 32.5 \text { (gr) }\end{array}$ & 450 & 450 & 450 & 450 & 450 & 450 & 450 & 450 & 450 \\
\hline River Sand (gr) & 1350 & 1350 & 1350 & 1350 & 1350 & 1350 & 1350 & 1350 & 1350 \\
\hline $\begin{array}{l}\text { Textile fibres } \\
(\%)\end{array}$ & 0 & 0,2 & 0,4 & 0,6 & 0,8 & 1 & 1,2 & 1,6 & 2 \\
\hline $\begin{array}{l}\text { Textile fibres } \\
\text { (gr) }\end{array}$ & 0 & 1,75 & 3,5 & 5,25 & 7 & 8,75 & 10,5 & 14 & 17,5 \\
\hline Water (ml) & 225 & 225 & 225 & 225 & 225 & 225 & 240 & 240 & 250 \\
\hline $\begin{array}{l}\text { Consistency } \\
(\mathrm{cm})\end{array}$ & 12 & 11,9 & 11,8 & 11,6 & 11,3 & 11 & 11,7 & 11,5 & 11,7 \\
\hline
\end{tabular}

Mixtures $\mathrm{F} 1(\mathrm{w})-\mathrm{F} 8(\mathrm{w})$ contained the same materials, at the same proportioning as the series $\mathrm{F} 1(\mathrm{nw})$ $\mathrm{F} 8(\mathrm{nw})$. The only difference is that the (nw) series contained non washed textile fibres, while the $\mathrm{F} 1(\mathrm{w})-\mathrm{F} 8(\mathrm{w})$ one contained water washed textile fibres.

\section{RESULTS}

Laboratory results are showed in Tables 2 and 3, for non-washed and water washed textile fibres respectively.

\section{Consistency and bulk density}

The consistence of freshly mixed mortars has been measured according to EN1015-3 by the use of a flow table. The flow value for the test sample was the mean value of two measurements for each composition. It was found that addition of textile fibres caused a decrease in consistency of the examined mixtures. 
Dry bulk densities for all mortars - modified or not - mixtures were determined by means of geometrical measurements and weighting according to EN1015-6.

Due to textile fibers' low specific gravity, when the percentage of textile fibres increases in the mixture, the dry bulk density of the composite decreases.

Table 2. Results of cement mortars with non-washed textile fibres

\begin{tabular}{lccccccccc}
\hline \multicolumn{1}{c}{ Property } & $\mathbf{F 0}$ & $\mathbf{F 1}(\mathbf{n w})$ & $\mathbf{F 2}(\mathbf{n w})$ & $\mathbf{F 3}(\mathbf{n w})$ & $\mathbf{F 4}(\mathbf{n w})$ & $\mathbf{F 5}(\mathbf{n w})$ & $\mathbf{F 6}(\mathbf{n w})$ & $\mathbf{F 7}(\mathbf{n w})$ & $\mathbf{F 8}(\mathbf{n w})$ \\
\hline $\begin{array}{l}\text { Bulk Density } \\
\left.(\mathrm{gr} \mathrm{cm})^{-3}\right)\end{array}$ & 2.19 & 2.17 & 2.16 & 2.14 & 2.13 & 2.10 & 2.08 & 2.06 & 2.05 \\
\hline $\begin{array}{l}\text { Dynamic modulus } \\
\text { of elasticity } \\
(\mathrm{GPa})\end{array}$ & 39.8 & 36.4 & 35.1 & 33.5 & 32.9 & 30.6 & 28.8 & 26.7 & 25.4 \\
\hline $\begin{array}{l}\text { Flexural strength } \\
\text { (MPa) }\end{array}$ & 8.10 & 7.60 & 7.50 & 7.30 & 7.10 & 7.00 & 6.90 & 6.40 & 5.90 \\
\hline $\begin{array}{l}\text { Compressive } \\
\text { strength } \\
\text { (MPa) }\end{array}$ & 39.6 & 37.5 & 36.0 & 35.6 & 35.1 & 32.5 & 29.8 & 28.5 & 26.2 \\
\hline
\end{tabular}

Table 3. Results of cement mortars with water washed textile fibres

\begin{tabular}{lccccccccc}
\hline \multicolumn{1}{c}{ Property } & $\mathbf{F 0}$ & $\mathbf{F 1 ( w )}$ & $\mathbf{F 2}(\mathbf{w})$ & $\mathbf{F 3 ( w )}$ & $\mathbf{F 4 ( w )}$ & $\mathbf{F 5}(\mathbf{w})$ & $\mathbf{F 6}(\mathbf{w})$ & $\mathbf{F 7}(\mathbf{w})$ & $\mathbf{F 8 ( w )}$ \\
\hline $\begin{array}{l}\text { Bulk Density } \\
\left(\mathrm{gr} \mathrm{cm}^{-3}\right)\end{array}$ & 2.19 & 2.17 & 2.16 & 2.14 & 2.13 & 2.10 & 2.08 & 2.06 & 2.05 \\
\hline $\begin{array}{l}\text { Dynamic modulus } \\
\text { of elasticity } \\
(\mathrm{GPa})\end{array}$ & 39.8 & 38.15 & 36.95 & 35.2 & 34.15 & 31.69 & 29.15 & 27.1 & 25.77 \\
\hline $\begin{array}{l}\text { Flexural strength } \\
\text { (MPa) }\end{array}$ & 8.10 & 8.10 & 8.00 & 7.70 & 7.40 & 7.20 & 7.00 & 6.50 & 6.00 \\
\hline $\begin{array}{l}\text { Compressive } \\
\text { strength } \\
\text { (MPa) }\end{array}$ & 39.56 & 39.05 & 37.86 & 37.05 & 36.77 & 33.89 & 30.05 & 28.62 & 26.20 \\
\hline
\end{tabular}

\section{Dynamic modulus of elasticity and mechanical strengths (compressive and flexural)}

Mechanical properties such as compressive and flexural strengths of conventional and modified with textile fibers composites were evaluated on prismatic $40 \times 40 \times 160 \mathrm{~mm}$ test samples, in compliance with the operating methods in standard EN1015-11, while dynamic modulus of elasticity was determined by measuring the time the ultrasonic waves need to bypass the test specimen. For the determination of the compressive strength the pieces of the prisms remaining after flexural test were used. At each age, three samples $(40 \times 40 \times 160 \mathrm{~mm})$ were tested in order to find the average value for the flexural strength and then the six pieces were tested in compression. According to laboratory results mechanical characteristics of cement mortars were almost the same with the conventional one or slightly worse for the mixtures $\mathrm{F} 1(\mathrm{w})-\mathrm{F} 6(\mathrm{w})$. For the rest of the mixtures, which means for textile fibres more than $1 \%$ of the matrix volume, the strength was found to decrease up to $33.9 \%$ compared to the conventional one for compressive strength, $27.16 \%$ for flexural strength and $36.05 \%$ for the dynamic modulus of elasticity. Mixtures, containing water washed textile fibres showed better behavior since the loss in compressive and flexural strengths as well as in dynamic modulus of elasticity was $33.7,25.9$ and $35.3 \%$ respectively. It should be noted that for $0.8 \%$ per volume, mixtures behaved quite well, since the losses in mechanical characteristics came up to $7 \%$.

\section{Water absorption and capillarity by suction}

The measurements were taken in compliance with the recommendations of RILEM CPC 11.3-for water absorption- and Normal 11/85-for capillarity by suction-, respectively, at the age of 28 days.

As far as water absorption is concerned, addition of textile fibres lowered the amount of water entering the specimen, for volume proportions of fibres up to $1 \%$. After that, the specimens tended to absorb more water with the addition of higher volumes of textile fibres. For the specimens, 
containing washed textile fibres, the tendency of absorbing water was the same as previously. However, these mixtures were found to absorb less water than the ones with non-washed textile fibres, as seen in figure 1.

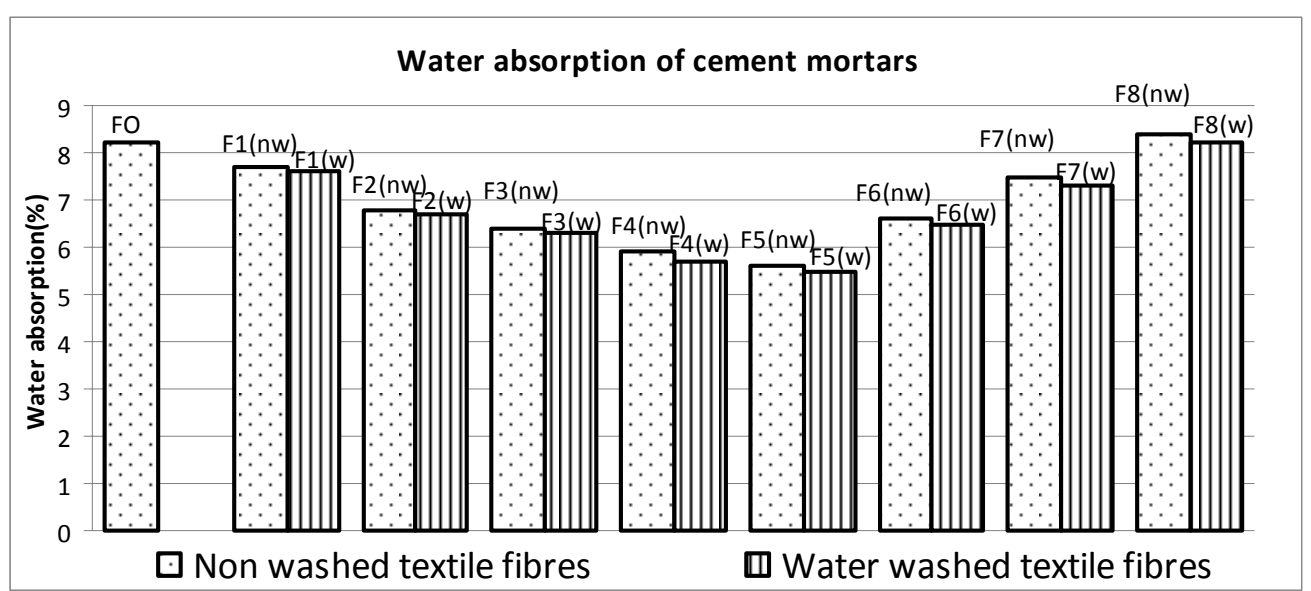

Figure 1. Water absorption of all the mixtures (with non washed and with water washed textile fibres)

For capillarity by suction, the test was carried out on a series of samples composed of three elements each with $4 \times 4 \times 16 \mathrm{~cm}$. The samples, after drying in an oven at temperatures of $100+5{ }^{\circ} \mathrm{C}$ and were cooled in room temperature until a constant weight was obtained. After calculating the weight of the dried sample, it was placed vertically inside a small basin on a porous support made up of a packet of blotting paper thoroughly soaked with distilled water. The samples were taken out of the bath at pre-determined intervals $(0,5,10,15,30,45,60,120$ and $1440 \mathrm{~min})$, plugged with a humid cloth on the surface touching the water and then weighed. After each measurement, they were placed on the packet of blotting paper again. The values obtained from the experiment made it possible to draw capillary absorption curves.

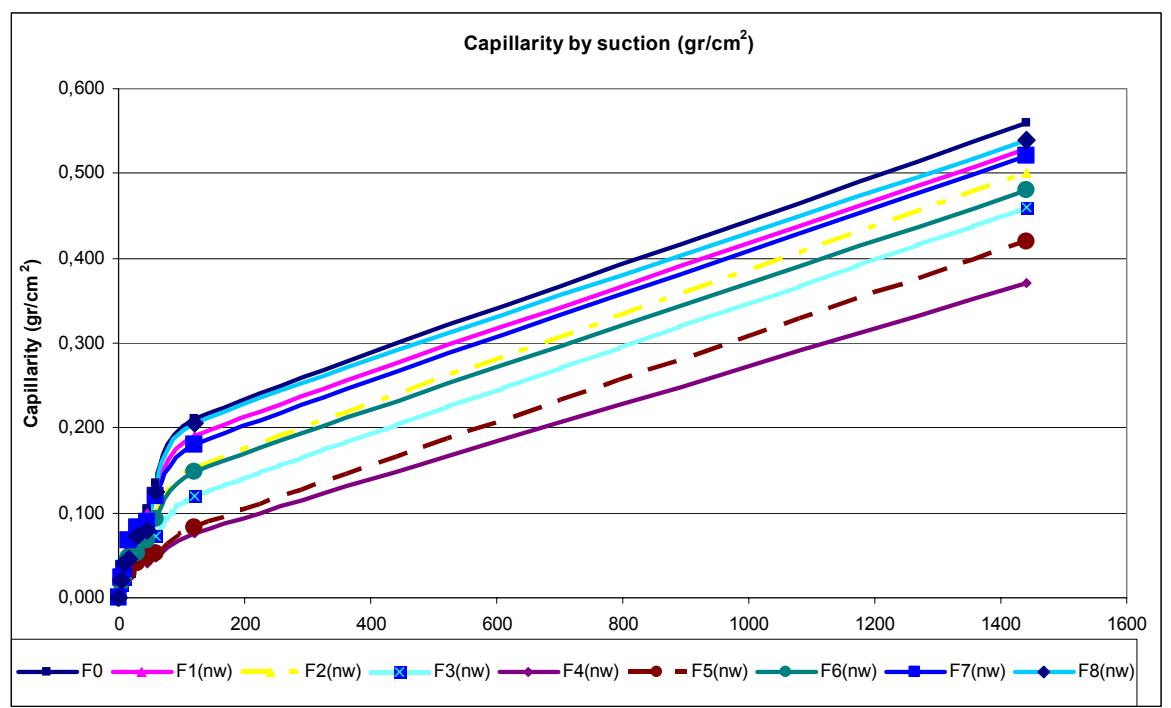

Figure 2. Capillarity by suction of mortars with non-washed fibres

According to previous figures, it was found that compositions with water washed fibres absorb less water through capillarity than the mixtures with non washed fibres. Moreover, for all the mixtures, capillarity by suction is in accordance with water absorption. 


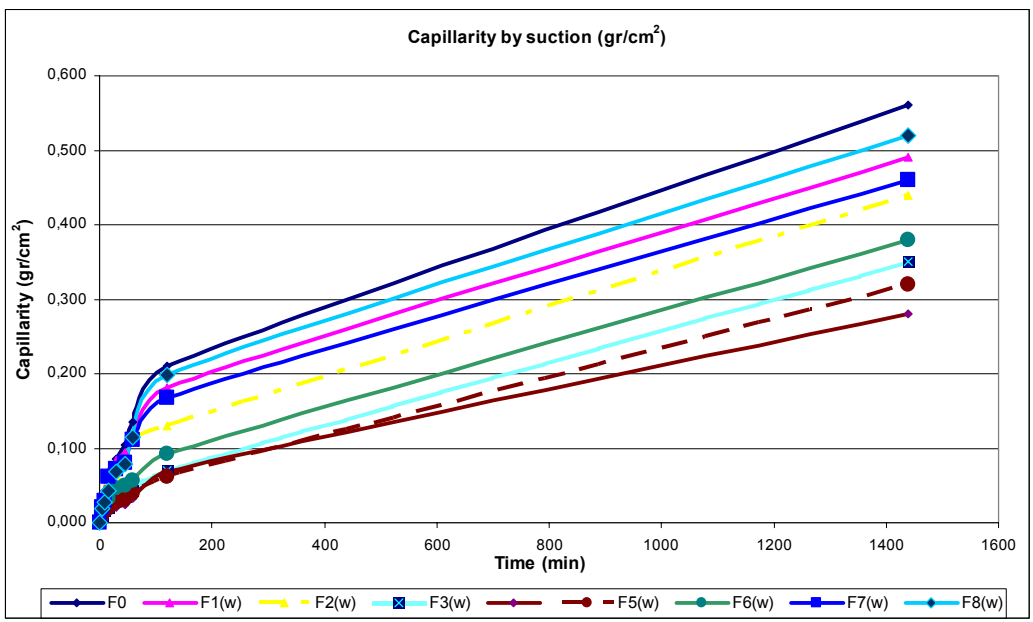

Figure 3. Capillarity by suction of mortars with washed fibres

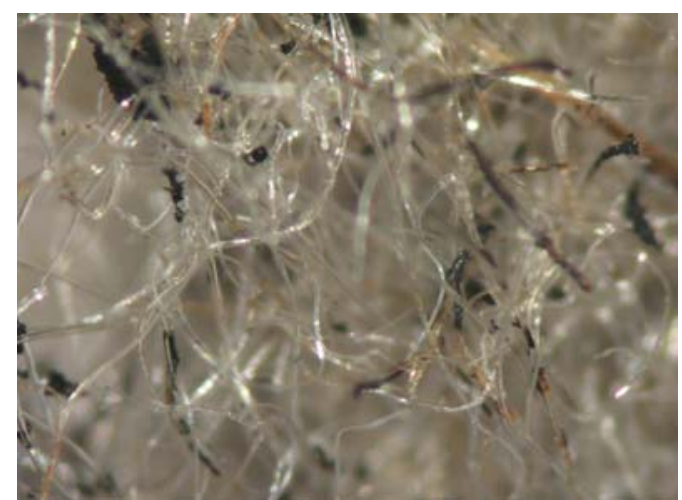

Figure 4. Textile fibres (stereoscope x5)

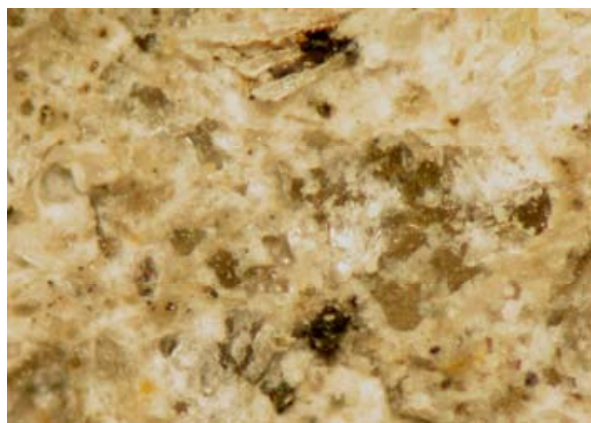

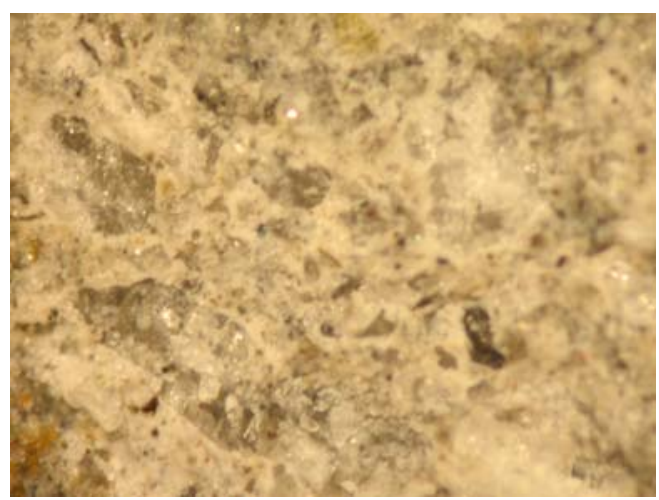

Figure 5. Conventional cement mortars (stereoscope $\times 2.5$ )

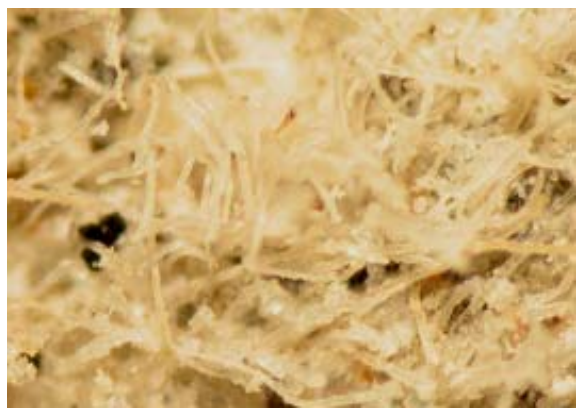

Figure $6 a-b$. Textile fibers modified cement mortars-F5(w) and F8(w) respectively (stereoscope $\times 2.5$ )

\section{Microstructure}

The examination of the microstructure of the test pieces has been conducted by the use of a stereoscope- STEMI $2000 \mathrm{C}$ and the magnification used ranged from 0.65 to 5.0 .

Firstly, textile fibres have been examined as seen in Figure 4 . Their width was measured at $<10 \mu m$, while they contained rubber particles in percentages up to $5 \%$.

The next step contained the examination of conventional cement mortar. This one showed that there is a perfect adhesion between river sand and cement paste (Figure 5).

Following, the microstructure of the modified with textile fibres cement mortars has been observed. It was observed that the fibres were well incorporated into the matrix, for the compositions $\mathrm{FO}(\mathrm{w})$ $\mathrm{F} 6(\mathrm{w})$. For the rest ones, $\mathrm{F} 7(\mathrm{w})-\mathrm{F} 8(\mathrm{w})$, which contained fibres at higher percentages, fibres were not well distributed into the matrix, causing greater losses in mechanical strengths and affecting negatively water absorption and capillarity by suction. 


\section{CONCLUSIONS}

Bulk density and consistency of cement mortars with textile fibres (treated or untreated with water) was found to decrease as the amount of the fibres increases. The decrease came up to $8.3 \%$ for up to $1 \%$ per volume textile fibres, keeping constant the ratio w/c (water/cement).

Moreover, mechanical characteristics of such mixtures were found to be familiar to the conventional ones. For the mixture with non treated textile fibres at percentage of $0.2 \%$ per volume the loss in compressive, flexural and dynamic modulus of elasticity came up to $5.3 \%, 6.1 \%$ and $8.5 \%$ respectively. However, mixtures with water washed textile fibres at the same percentage showed improved characteristics, which means loss of $1.23 \%, 0 \%$ and $4.14 \%$, respectively.

Water absorption and capillarity by suction of the mixtures with textile fibres were found to be improved. The reduction in the amount of water entering the mortars came up to $29 \%$ for $1 \%$ textile fibres compared to the conventional one. For bigger amount, the reduction did not exceed $18 \%$ for textile fibres at percentages from 1 to $2 \%$ per volume. Mortars containing water washed textile fibres behaved better, and the reduction in water absorption came up to $33 \%$ and $20 \%$ respectively.

So, addition of small amounts of water washed textile fibres (up to $1 \%$ ), provides mixtures with satisfactory physical and mechanical characteristics, suitable for construction purposes, while even higher percentages of fibres - up to $2 \%$ - (treated or untreated with water), can be used in cases waterproofing ness is demanded. In that way, a waste can be utilized and hence protection of the environment can be achieved.

\section{REFERENCES}

EN 1015-3:1999 Methods of test for mortar for masonry - Part 3: Determination of consistence of fresh mortar (by flow table). CEN European Committee for Standardization, Central Secretariat: rue de Stassart 36, B-1050 Brussels

EN 1015-6:1999 Methods of test for mortar for masonry- Part 6: Determination of bulk density of fresh mortar. CEN European Committee for Standardization, Central Secretariat: rue de Stassart 36, B1050 Brussels

EN 1015-11:1999 Methods of test for mortar for masonry - Part 11: Determination of flexural and compressive strength of hardened mortar. CEN European Committee for Standardization, Central Secretariat: rue de Stassart 36, B-1050 Brussels

E.T.R.A., EUROPEAN TIRE RECYCLING ASSOCIATION, http://www.etra-eu.org/

Karabas S.A, European Hellenic Recycling; http://www.karabas.gr/gr_index.html

Nehdi, M. and Khan, A. (2001) Cementitious Composites Containing Recycled Tire Rubber: An overview of Engineering Properties and Potential Applications, Cement, Concrete and Aggregates, CCAGDP, 23(1), 3 - 10.

NORMAL 11/85, "Assorbimento d'acqua per capillarità. Coefficiente di assorbimento capillare" CNR-ICR, Roma, 1985.

Oikonomou N. and Mavridou S. (2008) Rubcrete - Rubberized Portland Cement Concrete, In: Progress in Sustainable Development Research, Lopez R.A.(ed.), Nova Science Publishers, pp. 201-214.

Oikonomou N., Eskioglou P. and Mavridou S. (2007) Study of concrete kerb units modified with tire rubber, 4th International Conference "Bituminous Mixtures and Pavements", pp. 689-700,19-20/4/2007, Thessaloniki.

Presidential Decree No.109 Means and terms for alternative management of worn mobile tires, Program for their alternative management', 5th March 2004, Paper of Government of Hellenic Democracy, $1^{\text {st }}$ Part, 5 March 2004.

RILEM-TC/14-CPC: "CPC 11.3 (1984) Absorption d'eau par immersion sous vide / Absorption of water by immersion under vacuum", Materials and Structures, 17(101), pp. 391-394, ISSN: 1359-5997, RILEM Publications SAR.

Sukontasukkul P., Chalermphol Ch., (2006) Properties of concrete pedestrian block mixed with crumb rubber, Construction and Building Materials 20, 450-457.

TITAN S.A. http://www.titan.gr.

Topçu, I.B. (1995) The properties of rubberized concrete, Cement and Concrete Research, 25(2), 304310. 